\title{
Entre fala e língua, drama e texto: reflexões acerca de uma discussão contemporânea ${ }^{1}$ \\ Theresia Birkenhauer ${ }^{1}$
}

\section{Resumo}

O presente trabalho discute a pertinência da diferenciação entre escrita dramática e não-dramática e aponta a importância de práticas cênicas na criação dessa fronteira. A autora sugere que nas práti cas tidas como dramáticas, não se trabalha cenicamente com a linguagem, mas usa o texto como pré-texto do jogo ficcional. Por outro lado, as práticas não-dramáticas colocam no centro da atenção o impacto da estrutura lingüística sobre a percepção humana, bem como o palco enquanto espaço de expor esse trabalho interpelativo da língua sobre a percepção e consciência humana.

PALAVRAS-CHAVE: Teatralidade textual - escrita teatral - teatro dramático - teatro pos-drámático

\section{Abstract}

This paper discusses to what extent it is pertinent to diferentiate

between a dramatic and a non-dramatic writing. It points out the importance of theatrical practices in creating this distinction.

The author suggests that in theatrical practices perceived as dramatic, language is not the main focus. It is put at the service of fictional play. On the other hand, non-dramátic practice focus the impact of linguistic structure on human perception as well as the stage as the space to expose this interpelation of human consciousness and perception through language.

KEY WORDS: Textual theatricality - theatrical writing - dramatic theatre - postdramatic theatre

\footnotetext{
${ }^{1}$ Título original: "Zwischen Rede und Sprache, Drama und Text. Überlegungen zur gegenwärtigen Diskussion." In: BAYERDÖRFER, Hans-Peter et. al. Vom Drama zum Theatertext? Zur Situation der Dramatik in Ländern Mitteleuropas. Tübingen: Max Niemeyer, 2007. Tradução: Stephan Baumgärtel, professor do Departamento de Artes Cênicas e do PPGT/UDESC.
} 
liberar seus elementos do enquadramento inscrito neste, especialmente da relação de uma sucessão temporal. Desta forma, mantenho-me fie ao ponto de interrogação após o título do congresso.

Desde os anos 60 estão aumentando as propostas terminológicas para substituir o conceito de drama: "substrato textual literário", , "peça teatral" "literatura teatral" 5 . Algo semelhante vale para o conceito de personagem. Sugerese falar antes em "portadores de texto" "instâncias de discursos" ou "instâncias locucionais" ${ }^{\prime \prime}$. Essas substituições apontam para mudanças fundamentais. $\mathrm{O}$ velho juizo que afirmava que um texto é "inapto para o palco" não é mais válido. Hoje em dia, não existem mais textos que seriam "impossíveis de serem apresentados no palco" por causa de características especificas de seu gênero ou de sua forma. Textos em prosa, romances, epopeias, poemas, radiodramas: todo tipo de texto está sendo 'realizado' no palco, sem passar por um 'dramatização' no sentido usuário - o Velho Testamento bem como o bestseller da última temporada, roteiros de filmes ou textos de autores famosos que não foram escritos para o palco. Os textos teatrais recentes não podem mais ser classificado por meio das características tipológicas do drama, nem por respeitar estruturas dialógicas, nem por seguir outros elementos formais deste.

Frente a essa prática teatral contemporânea, a questão sobre se $o$ teatro precisa do texto ou deveria prescindir dele para li-

2PFisTer, Manfred. Das Drama. München: Fink, 19885, p.28. 3 DYES, Klaus-Müller. Gattungsfragen. In: ARNoLD, Heinz-Ludwig
e DETERRING, Heinrich: Grundzüge der Literaturwissenschaft. Müne DETERING, Heinrich: Gris.
chen: DTV, 1996, p.343.

PoschManN, Gerda. Der nicht mehr dramatische Theetertert.

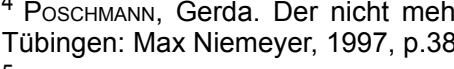

LEHMANN, Hans-Thies. Postdramatisches Theater. São Paulo: Cosac \& Naify, 2007, p.5

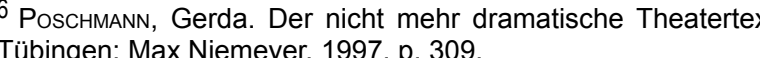

7 KEIM, Katharina. Theatralitït in den späten Dramen Heiner Mü-
lers. Tübingen: Max Niemeyer, 1998, p.55 bertar a sua própria característica artística, que era uma polêmica na época das vanguardas teatrais, não constitui mais uma alternativa antitética.

Parece que o velho conflito entre teatro e literatura chegou ao fim. Mesmo as tradicionais fronteiras culturais, que por muito tempo propiciaram uma orientação, (que o teatro do texto seja o teatro institucional concebendo-se como instituição da formação literária, enquanto o teatro experimental seja "antiliterário" ou "além do texto") não servem mais.

\section{Dramático - Pós-dramático}

Perante essas transformações, as teorias recentes do drama propuseram uma diferenciação que implica concomitantemente em uma periodização histórica: a distinção entre formas teatrais dramáticas e pós-dramáticas, entre textos dramáticos e textos teatrais não-mais dramáticos.

$O$ que se afirma é uma cesura entre o teatro dramático - enquanto lugar de personagens que falam no contexto de ações ficcionais - e o teatro pós-dramático, enquanto lugar de discursos polifônicos e de significantes soltos. A essa concepção junta-se uma tese sobre a função da língua. No teatro dramático, assim ela diz, o texto apresenta os esboços de ação para um acontecimento ficcional e é texto de um personagem (portanto, fala figurativa). Textos teatrais além do drama, no entanto mostram uma tematização autorreflexiva da língua e deveriam ser lidos enquanto "poesia": Libertado da polifuncionalidade fundamental da comunicação cotidiana, ou seja, da comunicação puramente referencial de informações, a linguagem no texto teatral pode ativar preferencialmente a função poética de seus signos.

Essa atribuição retoma uma diferencia-

8 PoschmAnN, 1997, p.323. A "funçãa poética" é compreendida
enquanto "funçăa autorreflexiva" e explicita da seguinte forma "O que aflora no centro do interesse [do leitor e do espectador por meio da funçãao poética da linguagem, são os processos da prática semiótica e da constituição de significados no uso de de terminado código. O uso poético da linguagem, enquanto sua
auto-reflexão, é ao mesmo tempo meta-linguistico e meta-teatral." ção mais antiga, no entanto com outra ênfase. Tradicionalmente, se relacionava com oposição entre "dramático" e "poético" uma fronteira entre gêneros literários. Uma vez que a palavra, em textos teatrais, não possui sua eficácia por si só - como na fala lírica - mas no diálogo das personagens, tem-se afirmado uma incompatibilidade entre a escrita 'dramática' e a 'poética', respectivamente uma limitação da 'função poética'. Neste sentido, Käthe Hamburge diz: "[...] o drama é aquela obra de arte verbal, na qual o verbo não está mais livre, mas contextualizado. [...] A fórmula dramática, que diz que o verbo é colocado para dentro do contexto da forma, diz que o lugar do drama deve ser definido, em primeiro lugar, em relação ao problema da forma, e não à palavra em si." ${ }^{11}$

As teorias mais recentes do drama também atestam aos textos teatrais um "uso poético da linguagem", no sentido de que eles não se definem pelo representado, mas se referem ao seu próprio acabamento formal e ao processo teatral da representação e da percepção."

Por isso, pode-se perceber nas concepções teóricas acerca do teatro pós-dramático um interesse renovado no teatro lírico e simbolista da virada para o século XX. Diz se que no drama inicial de Maeterlinck, "renuncia-se a toda a estrutura de tensão, drama, ação e imitação" ${ }^{12}$, "não era mais o texto para os papéis que se considerava como a essência do texto teatral - como ocorria no teatro dramático -, e sim o texto como poesia, que por sua vez deveria corresponder à própria 'poesia' do teatro."

Mas o que qualifica uma fala dramática enquanto "texto para um papel"? O que a qualifica enquanto "poesia"? A tese dos gêneros diz que é a referência da fala dramática a um contexto de ações, que a torna "texto para um papel". Onde se renuncia

${ }^{9}$ LaRTHOMAs, Pierre. Le Langage dramatique. Sa nature, ces pro-
cédés. Paris: PUF, 1980, p.438. 10 HAMBURGER, Käthe, Kate. Die Logik der Dichtung Stuttgart, Klett, 1969², p. 161. (A Lógica da Criaçăoo Literária, ${ }_{11}^{1}$ Poschmann, 1997, p.130 e p. 340

12 LeEMANN, 2007, p.95.

${ }^{13}$ LeHMANN, 2007, p.97. "as axiomas dramáticas de ação", onde a linguagem dramática é libertada da função de caracterizar e diferenciar pessoas, onde fala não se refere mais a personagens, ali há 'poesia'. Mas isso significa, inversamente, que não há "poesia" onde existe um contexto dramático de ação, personagens ficcionais, indicações de fala referentes pessoas? Essa conclusão inversa mostra o quanto tal definição conceitual é discutível. Ela aponta a dificuldade de uma delimitação que torna o "poético" uma característica de textos teatrais que desconhecem a fala figurativa e um contexto de ação.

É impossível decidir, pela superfície formal, se um texto dramático é "poesia" ou "texto para um papel". Nas peças de Tchekhov ou Koltés há "texto de personagem". Entretanto, a fala dramática neles não se refere exclusivamente a personagens ou ações. Por outro lado, didascálias de interlocutores que apontam a uma despersonalização - como, por exemplo, "o velho", "o estrangeiro", "primeiro, seguno, terceiro cego" nas peças de Maeterlinck - não diferem fundamentalmente de indicações figurativas dos papéis em Beckett ou Thomas Bernhard. Nesses casos, não nada óbvio se os interlocutores são, de fato, pessoas, mesmo que sejam denominados enquanto tais. Fica explícita a dificuldade de definir características formais de textos dramáticos ou não-dramáticos com categorias fixas. Nenhum texto dramático prescreve como deve ser lido; se um texto é denominado "poético" ou não, não é determinado por um caráter que possa ser definido conceitualmente como "dramático" ou "não-dramático" em si. O poético é uma dimensão da linguagem dos textos que pressupõe, para ser materializada, uma deerminada prática de leitura ou montagem que produz ou revela essa dimensão - ou

A tentativa de uma definição inequívoca de características do "dramático" corre o risco de identificar convenções de encenação com a forma literária dos textos. Uma caracterização da função de texto no drama principalmente através das proprieda- 
des "fala de personagem" e "referência do diálogo à ação", remete em primeiro lugar a uma determinada prática de encenação. Tanto a concepção de que a fala de uma personagem representa uma expressão natural, quanto à afirmação de que a linguagem em textos dramáticos é, sobre tudo, um meio de comunicação e sua função transmissão de conteúdos discursivament descritíveis, são atribuições que surgiram por causa de convenções de encenação do teatro ilusionista burguês. Somente ess tradição de montagem criou estas suposições básicas, supostamente fundamentais, acerca da função do texto dramático segundo as quais a linguagem no drama implica, em princípio, a fala individual de uma personagem; fala monológica ou dialógica de caracteres representados. Determinar as características de textos por meio dos modos de apresentação do teatro ilusionista implica em defini-las através de uma prática de encenação a qual eles não pertencem nem exclusivamente, e muito menos necessariamente.

Enquanto se entende a fala dramática primordialmente na sua dimensão comunicativa, ou seja, enquanto mimese de um fala individual, o texto falado se referirá às dramatis personae: Como são criadas as personagens? O que acontece entre elas? $\mathrm{O}$ que elas revelam sobre si mesmas? Negligencia-se o fato de que também os texto dialógicos não são escritos exclusivamente enquanto textos da fala das dramatis personae, mas igualmente enquanto textos par o palco teatral. ${ }^{14}$ Enquanto textos para o teatro, entretanto, eles possuem um duplo ponto de referência: no que concerne a seus elementos, os textos dramáticos se relacionam com uma cena a ser representada, uma ação, uma interação, mas em seu cálculo compositório se relacionam com o processo de apresentação, com a percepção do espectador. Isso tem a ver com a estrutura fundamental da apresentação teatral: a perspectivização dupla da fala dramática.

${ }^{14}$ Isso não quer dizer que sejam escritos para uma determinad cão, mas sim afirmar o vinculo da composição dos textos com a estrutura da apresentação teatral.

\section{A dupla perspectivização}

Segundo um consenso entre todas as teorias, a simultaneidade de duas perspectivas é fundamental para o teatro. Ela é descrita de modo diverso: enquanto "função dupla" da fala dramática, que é sempre endereçada duas vezes, às personagens e ao público; enquanto sobreposição da perspectiva das personagens e dos espectadores; ${ }^{16}$ enquanto "sobreposição imediata dos sistemas comunicativos interno e externo"; $;{ }^{17}$ enquanto "eixo de comunicação intracênico" e "um eixo ortogonal que diz respeito à comunicação entre o palco e o local da plateia, diferenciado (real ou estruturalmente) do palco". ${ }^{18}$

Quais são as consequências dessa perspectivização dupla? Tradicionalmente, se atribui o "texto principal" - as falas das personagens - ao sistema de comunicação "interno". O "texto coadjuvante" - as indicações sobre os interlocutores, as didascálias, definições de atos, de entradas e saídas de personagens - é atribuído ao sistema de comunicação "externo", como se as falas das personagens não fossem submetidas também a um raciocínio formal de apresentação. Nas citadas abordagens da teoria do drama, a relação dos dois eixos se transforma em critério de periodização: a literatura dramática tradicional deve-se compreender a partir do sistema de comunicação interno - enquanto representação de ações ficcionais no palco, ao passo que o tipo textual não-dramático" se refere à comunicação externa, à plateia. Em relação às formas teatrais pós-dramáticas, se diz “Dessa conhecida duplicidade de todo teatro, o teatro pós-dramático extraiu a consequência de que em princípio deve ser posdesaparecimento e ativar a segunda para lograr uma nova qualidade de teatro. [... O teatro é enfatizado como situação, não como ficção." ${ }^{19}$

15 Larthomas, 1980, p.437: «La replique la plus banale est desti${ }^{16}$ Hamburger, 1969, p.164.

17 Pfister, 1988, p.24

${ }^{18}$ Lehmann, 2007, p. 211

${ }^{19}$ Lehmann, 2007, p. 212
Mas esta periodização, que encaixa o a característica formal do drama. Em sua drama em seu universo intraficcional - a esteira, a literatura dramática aparenta ser "realidade autônoma da ficção dramática" determinada pelas propriedades de "totali- e as formas não dramáticas na comunicação externa - "a situação teatral real" prescreve, para a literatura dramática, uma fronteira que dificilmente pode ser sustentada a partir de uma perspectiva histórica do teatro. A dupla perspectivização é constitutiva para o teatro. Se ela é negada por causa de convenções estéticas do teatro, por exemplo na reivindicação da quarta parede no teatro burguês, isso não significa que não havia a "comunicação externa" o endereçamento à plateia. O espectador é endereçado enquanto observador clandestino, que é excluído do acontecimento.

A comunicação externa não implica simplesmente no endereçamento ao espectador real, mas a formação dessa relação, a perspectivização daquilo que é representado. Mesmo a atitude descrita por Szondi de modo tão drástico, segunda a qual o espectador do drama congela numa "passividade total", "calado, com os braços cruzados, paralisado pela impressão de um segundo mundo", ${ }^{20}$ não implica que não haja um endereçamento da representação para o espectador. Se e por meio de quais formas se realiza este endereçamento no eixo palcoplateia, se de modo explícito ou embutido em uma estrutura dialógica que parece endereçar-se exclusivamente aos acontecimentos representados, depende de convenções teatrais dramatúrgicas e estéticas.

Se reconhecemos a tematização do eixo palco-plateia apenas onde há um endereçamento fatual e explícito ao público - ou seja, predominantemente nas formas teatrais da vanguarda e neovanguarda do século XX incorremos em ignorar uma das forças formadoras determinantes fundamentais de textos dramáticos. Textos escritos na tradição do drama não são exclusivamente endereçados à "ação intraficcional". Quem se atém a isso identifica determinada prática de encenação com uma relação desses dois eixos e a prescreve, posteriormente, como

\section{${ }^{20}$ Szondi, Peter. Teoria do drama moderno. 1880-1950. São
Paulo: Cosac \& Naify, 2001, p.31.}

ENTRE FALA E LÍNGUA, DRAMA E TEXTO: REFLEXÕES ACERCA DE UMA DISCUSSÃO CONTEMPORÂNEA ade ilusão e representação do mundo", ou respectivamente por ficção, ação e mímese - enquanto "apresentação de uma história de personagens que se estende no paço e no tempo".

Outro entendimento resulta se pensarmos cada encenação como uma nova determinação desses eixos. A consequência disso é diferenciar entre estruturas textuais modos de encenação e historizar rigorosamente as características tipológicas. Faz uma grande diferença se pensamos o teatro exclusivamente enquanto "realidade do palco" - enquanto realização empírica e textos, segundo certas convenções de encenação - ou enquanto uma estrutura de presentação que organiza textos teatrais de modo específico. Isso transforma a perspectiva sobre os textos tanto quanto as en(Eços. Em relação a textos dramáticos, sso significa não imputar-lhes de antemão ma determinada relação - por exemplo, a hegemonia do eixo intraficcional - mas desenvolver uma relação específica entre os dois eixos a partir de suas estruturas textuais. Neste caso, os textos dialogados não os de modo intradramático, em relação as dramatis personae - enquanto falas, que s caracterizam, que lhes atribuem um contorno e expressam seu estado de ânimo cons simultaneamente enquanto textos que constituem a estrutura dramática da apreentação ao configurar a relação dos dois os de modo específico.

Pode-se observar isso tanto no drama dextos dramáticos centes. Na virada para o século $X X$, o tracom essas duas camadas é explícito or exemplo, em Tchekhov e Maeterlinck. Mas pode-se percebê-lo igualmente em Koltés, cujas peças possuem característicola de personagem e o vínculo dela com a ação dramática - de textos dramáticos. Entretanto, elas manuseiam de modo muito sutil a dupla perspectivização da 
fala dramática. O diálogo nunca se resolve na sua dimensão referencial intraficcional. Sempre são expostos também gestos verbais, retóricas e estratégias que concomitantemente estruturam nossa percepção do espaço cênico e as qualidades temporais. Por outro lado, devemos indagar nas encenações como cada uma acentua esses dois eixos do teatro de modo particular. Neste sentido, devemos compreender encenações - num sentido mais específico do que o comum - enquanto leituras que realizam aquele potencial em textos dramáticos que uma leitura exclusivamente direcionada ficção dramática negligencia: a dupla perspectivização da fala teatral.

\section{Entre fala e língua}

Podemos observar, de modo exemplar potencial cênico ${ }^{23}$ de um trabalho com o dois eixos naquelas encenações que montam textos que, segundo suas características tipológicas, seriam textos dramáticos, como por exemplo a montagem de Woyzeck de Büchner, realizada por Michael Thalheime no Thalia Theater em Hamburgo (2003). A encenação de Thalheimer expõe a perspectivização dupla ao distanciar radicalment os dois eixos - o intracênico e o extracênico.

Um meio básico do qual a encenação ança mão consiste em renunciar do modo de atuação realista, de sua correspondência entre gestos e voz, entre forma corpora e fala. Nunca se articula os textos segundo as regras da entonação semântica - como se articulassem estados de ânimo ou intenções dos personagens - mas sempre como elementos de uma composição de encenação que a estabelece como dispositivo espacial abstrato do palco. Isso produz transformações na relação entre cena e língua. Ainda que haja uma sequência linear de cenas, é abandonada a relação de ação dra-

23 Em alemão: Darstellungspotential. O verbo darstellen nầ palmente "tornar concreto ou colocar perante os olhos algo que existe na mente ou em outro lugar" e nessa dimensão inclui " "ta-s presentar". A atividade não se limita à atuação, mas uma das
palavras tradicionais para o ator em alemão ê Darsteller. (nota do tradutor) mática interna. Com isso, as réplicas perdem seu ponto de referência dialógico; ela se encontram no espaço sem endereçado e mesmo assim, apelam permanentemente a um outro, carregadas com um afeto que fica sem ressonância.

Normalmente, o modo específico da apresentação teatral fica camuflado por causa da orientação não-questionada na personagem falante e de uma corres pondência entre situação cênica e texto falado. Esta encenação subverte essa orientação ao tornar perceptível não a correspondência, mas a tensão entre os dois eixos. As réplicas são tiradas de qualquer relação intracênica e direcionadas diretamente para o público, mas não por meio de procedimentos conhecidos como o distanciamento, o comentário, endereçamento isolado, senão de modo estranho, pois as frases ficam, ao mesmo tempo, carregadas da excitação que lhes pertence a partir da dinâmica cênica.

Os procedimentos cênicos propulsionam um movimento no qual as frases ditas perdem seu "significado unilateral" que se refere à situação cênica. Elas são colocadas em um espaço que não pertence unicamente aos interlocutores. Elas se chocam diretamente com o espectador. Para ele, que não é interlocutor, mas um observador dessa fala, elas se tornam perceptíveis enquanto violência cortante, imploração, emoção que perdeu os suportes relacionais, afeto puro Enquanto ouvinte, o observador é exposto à violência dessa linguagem, sem a distância que lhe oferecem um contexto cênico e uma ambientação dramática.

A encenação realiza uma dimensão da língua que se livra da função descritiva comunicativa da fala dramática. Ela gera novos espaços de significação, de modo que a língua não é mais somente parte funcional da narrativa dramática, mas desenvolve um movimento próprio, que por sua vez transforma o acontecimento cênico. Desse modo, a encenação possibilita uma transformação e uma modelagem da fala teatral e com isso uma prática da linguagem própria do teatro.

\section{Encenar enquanto prátic \\ da linguagem}

Se compreendermos encenações enquanto leitura, no sentido explicitado por Michel de Certeau - enquanto "procedimento necessário para a realização da obra" - elas não aparecem mais como "interpretações" da direção, modos de ler pessoais, mas enquanto leituras que continuam o ato de escrever um texto dramático e desse modo transformam permanentemente o olhar sobre a fala dramática. Uma encenação não é classificada como leitura por acentuar conteúdo de textos de modos diversos que se associa com o "teatro do diretores" dos anos 70 - mas por organizar os textos cenicamente, para, dessa forma, "restaurar um determinado uso, mais abrangente mais radical, da palavra." ${ }^{24}$

Se analisarmos os procedimentos de encenação que geram essa dimensão da linguagem, perceberemos que realizam potenciais cênicos genuínos do palco. Os procedimentos são dos mais diversos: um deslocamento do sentido das palavra pela imagem, um modo específico de atuação, formas de espacialização da palavra criação de temporalidades heterogêneas. Entretanto, esses deslocamentos sempre impactam sobre a língua, colocam-na em cena" de forma diversa.

Nesse sentido, o teatro não é o lugar de uma concretização da literatura - no sentido comum de um teatro de literatura - mas ele mesmo é uma prática literária, contanto que as modalidades próprias do palco permitam um "trabalho na língua" (Barthes) que faz com que ela possa ser experimentada de modo diverso. Na encenação de Thalheimer, a língua aparece enquanto afeto condensado que praticamente cancela a função comunicativa do ato de dizer. Experiências com a língua totalmente diferentes foram realizadas pelo teatro de Heiner Müller, o teatro de Einar Schleef ou de

24 Merleau-Ponty, Maurice. "Der Mensch und die Widersetzlichkeit der Dinge". In: Das Auge und der Geist. Philosophisct-
Essays. Philosophische Essays." Hamburg: Rowohlt, 1984.

${ }^{25}$ Darstellungspotentiale, ver nota 23.
Elfriede Jelinek. O palco é um lugar em que surgem novos jogos de linguagem a cada encenação.

De um ponto de vista histórico, isso significa que encenações mudam permanentemente a relação entre os dois eixos da apresentação teatral. $O$ teatro francês clássico, por exemplo, podia ser lido diferentemente após montar as tragédias de Racine com sensibilidade pelas estruturas espaciais e pelas relações dos olhares, presentes nas práticas cênicas do século XVIII. Isso é válido também para textos teatrais. Os dramas de Koltés configuram um palco que renova o olhar para Corneille, os textos de Jelinek transformam nossa perspectiva sobre Hauptmann, as peças de Duras a sobre Maeterlinck.

Entretanto, isso não acontece inevitavelmente. Uma encenação não acentua $a u-$ tomaticamente a dupla perspectivização na estrutura da apresentação teatral. Encenaçoes certamente podem transformar texto teatrais em textos convencionais por reduzi-los ao "drama". Um exemplo recente é a estreia da peça Blues subterrâneo ${ }^{26}$ de Peter Handke, por Claus Peymann na Berliner Ensemble em 2004. A encenação aposta exclusivamente na dimensão intraficciona do texto; os espectadores veem um placo que representa, de modo realista e detalhado, uma daquelas polidas e assépticas estações de metrô sem nenhum funcionário, na qual trens dirigidos com controle remoto emitem sinais automáticos durante a parada. O "subterrâneo" aqui é brilhane bonito; as figuras - todas são vestidas de modo que já revelam sua tipificação por meio do figurino - entram no vagão. Lá está sentado "um homem selvagem", como diz a rubrica descritiva da figura. Esse homem comenta sobre os antigos e novos passageiros ao falar, sem restrições, o que lhe pass pela cabeça - palavrões, gentilezas, especulações, fantasias, pressuposições que lhe vêm à mente frente às personagens. Até em fim, entrar "uma mulher selvagem" que comprova a misantropia do homem. "Sim, exatamente assim acontece," pensa o

${ }^{26}$ Em alemão, Untertageblues. 
espectador dessa encenação e rapidamente fica com tédio. Em nenhum momento criase uma irritação. A situação visual é interpretada claramente através do texto, pois a encenação constrói, já de antemão, uma congruência entre a fala do homem selvagem e aquilo a qual ela se refere. A possível diferença entre a perspectiva do interlocutor e da situação cênica não é trabalhada na encenação, de modo que nem a qualificação da fala dada no título - enquanto Blues - nem o lugar de sua manifestação - o subterrâneo - se tornam claros. A personagem se mantém estranhamente rasa, não se transforma - nem por instantes - em uma das figuras metamorfoseadas que o texto menciona: um Tirésia, um Charon, um anjo negro. De fato, pouco resta desse monólogo interior, de sua motivação pelo outro e pelo próprio, de seu status ficcional ambivalente enquanto conversa consigo mesmo e endereçamento. A dupla perspectivização, embutida no texto de vários modos, está sendo nivelada em favor de uma evidência unilateral e inequívoca.

O que vale para as encenações se aplica, naturalmente, também aos modos de escrita. Eles também podem contornar ou evitar o potencial da perspectivização dupla, por meio de uma orientação direta demais nos temas a serem comunicados, no material ou nas teses. Não é por acaso que os festivais anuais de novas peças criam a impressão de que se tratam de produções cíclicas sobre os temas da pedofilia, da identidade da Alemanha Oriental, do incesto ou do desemprego. De fato, existem dramaturgos que se concebem enquanto fornecedores de temas para o teatro e que escrevem a peça a ser encenada pensando numa relação com a atualidade que há tempo é assumida por outros meios de informação.

Assim, surge a questão se devemos diferenciar entre textos literários e "textos teatrais", que reivindicam um status não literário, ou seja, de ser "material" ou "matriz" da atuação.

Propriedades formais (as formas dialogadas, relação com a ação, ficcionalidade) ou simples procedimentos dramatúrgicos (repetição, interrupção, modos de fala em forma de coro, a renuncia a personagens ou narração) não são critérios para dizer se um texto é teatral ou não. Antes, isso se decide pelo modo como e até que ponto trabalham com o potencial das estruturas da apresentação teatral. Tais textos, mesmo sendo dramas, são interessantes para diretores de hoje. Frank Castorf, por exemplo, liberta na sua encenação Estação Terminal América o clássico Um Bonde Chamado Desejo, de Tennesee Williams, de sua fixação como clássico do drama psicológico.

Ao invés de insistir no texto literário, dever-se-ia indagar que tipo de experiência de linguagem humana ele possibilita. O que faz do teatro um espaço da literatura não é o fato de que se montam textos literários. Teatro também pode se tornar um espaço para vivenciar a literariedade, onde não se encena textos literários, como nos trabalhos de Christoph Marthaler ou Ariane Mnouchkine. Não existe um significado prévio de textos que deveria ser "comunicado", realizado ou transposto pelas encenações. Tampouco poderia um conteúdo atribuído a um drama "desvendar" para o espectador o "sentido" de uma encenação. Isso pode unicamente a vivência estética desta.

Literatura, na compreensão de Roland Barthes, não é um atributo das obras, mas uma atividade, um "trabalho na língua" que se distingue da prática verbal comum. A língua não se revela por vontade própria. Por vontade própria, ela é o lugar das mensagens, do poder. Ela se revela, diz Barthes, "porque as forças de liberdade que residem na literatura não dependem da pessoa civil, do engajamento político do escritor [...] nem mesmo do conteúdo doutrinário de sua obra, mas do trabalho de deslocamento que ele exerce sobre a língua." 27 Por causa dessa estrutura dupla da fala dramática, o teatro é o espaço no qual é possível este "trabalho de deslocamento sobre a língua" e, com isso, a "revolução permanente da fala", que é a literatura.

\footnotetext{
${ }^{27}$ Barthes, Roland. Aula. Aula inaugural da cadeira de semiologia literária do Colégio de França. São Paulo: Cultrix, 1988, p.15-16.
} 